Mitja Skubic

Universidad de Ljubljana

\title{
LA GUERRA CIVIL EN ESPAÑA Y LA ESCISIÓN EN LA ESFERA CATÓLICA ESLOVENA: EDVARD KOCBEK
}

La comunidad eslovena, hoy en su mayoría reunida en la República de Eslovenia, en el tiempo del Imperio Austro-Húngaro estaba repartida en varios ducados: Carniola, Estiria, Carintia, Litoral Adriático. Después de la derrota del imperio, con la fundación del Estado de los Eslavos Meridionales, en 1918, llamado Reino de los Serbios, Croatas y Eslovenos, y desde 1929 Yugoslavia, continuó, en la política eslovena, aunque bajo etiquetaje diferente, la antigua división, mejor dicho, el contraste, a veces muy fuerte, entre las esferas clerical y liberal, evidente también en la actividad cultural.

No es sorprendente que la zona rural fuera por completo clerical bajo el influjo del clero; al contrario, en las ciudades el partido liberal ocupó una parte importante y a su lado, ya al final del siglo diecinueve, el naciente partido socialista y con él una mentalidad contraria al clericalismo. El papel dominante del clero en la vida política, de suma y por cierto de positiva importancia en los tiempos de Austria, cuando la nación eslovena luchaba por existir como nación, no fue de agrado a todos los católicos: pensaban muchos que tal actividad frenaba la verdadera fe. Así se anunciaba ya una escisión en el mundo católico esloveno: « clericalismo» fue en aquel entonces el término introducido y usado por los liberales y socialistas para el catolicismo político, es decir, para las ambiciones de la Iglesia eslovena, de la jerarquía eclesiástica, para que en la sociedad y en la política también gobernasen principios religiosos y morales católicos.

Una situación similar se produjo en el campo cultural. Desde el final del siglo anterior aparecieron obras literarias con temática social que llamaban la atención sobre el carácter nocivo de la orientación clerical; se podría decir que la mayoría de los escritores eslovenos era contraria a cualquier influjo clerical en el campo cultural. Por otro lado, la parte católica pudo contar con una serie de destacados creadores literarios que contribuyeron esencialmente a la formación de la imagen espiritual del esloveno. Y uno de los más importantes fue sin duda el escritor, filósofo y poeta Edvard Kocbek ${ }^{1}$ (1904-1981).

Nacido en Estiria, pasó, después de haber terminado la escuela media, casi dos años en la escuela de teología, pero la abandonó y se dedicó, en la Facultad de Letras de la Universidad de Ljubljana, al estudio de lenguas y literaturas románicas lo que en aquel entonces significaba sobre todo el estudio del francés. Para la formación del joven Kocbek la cultura francesa, no solamente la lengua y la literatura, tuvo una influencia fundamental. Antes y después de la Segunda Guerra Mundial fue notable su afición a la filosofía francesa, se destaca entre otras actividades su colaboración con la revista Esprit, de inspiración católica, mejor dicho, cristiana. Ya en el período estudiantil y más aún durante su permanencia en París, Kocbek tuvo contacto con los filósofos católicos franceses y dedicó muchas reflexiones suyas al concepto filosófico del personalismo cristiano con Emmanuel Mounier, a la fuerza creadora del individuo libre y éticamente responsable. Esprit profesaba un catolicismo de vanguardia. Para las orientaciones de Kocbek en el período de la ocupación nazifascista, no está, quizás, de sobra añadir que la publicación

1 La pronunciación en esloveno del apellido del escritor es [kótsbek]. 
de la revista fue suspendida en verano de 1941 por mantener una posición crítica hacia el Gobierno de Vichy.

Kocbek fue profesor de lengua francesa en Croacia y después en Ljubljana; era un personaje carismático y como tal orientaba espiritualmente a los jóvenes intelectuales eslovenos de inspiración católica. De toda su actividad y de las obras literarias emana una profunda y auténtica fe religiosa. En los últimos años antes del conflicto mundial publicaba en la prestigiosa revista eslovena Dom in svet (Hogar y mundo) (1888-1944), de marcada inspiración católica, que representaba en el mundo esloveno la parte más tolerante de la cultura católica. En 1937 Kocbek publicó en esta revista el ensayo Premišljevanje $o$ Španiji (Meditación sobre España), en el cual condenó la derecha católica española y también las altas capas de la Iglesia española por su colaboración con el franquismo y con el alzamiento contra la legítima institución republicana. La publicación provocó en la comunidad cultural eslovena católica - prefiero no decir «clerical», para evitar el término, en esloveno decididamente teñido políticamente - un verdadero terremoto, la escisión de la esfera cultural católica eslovena. La extrema derecha de la cumbre católica, esencialmente dogmática, empezó una ferviente campaña contra la revista y contra el autor que fue estigmatizado como «izquierdista», mientras que la revista tuvo que interrumpir su publicación por un año y el director France Koblar, personalidad distinguida del mundo católico esloveno, fue destituido por la presión de la extrema derecha católica eslovena. El año siguiente Kocbek fundó y, hasta la ocupación italiana de Ljubljana, dirigió la revista Dejanje (Acción) (1938-1941) de inspiración cristiano-social, que reunía muchos espíritus eslovenos y no solamente católicos. La revista, inspirada como Kocbek mismo en la revista católica francesa Esprit, profesaba un espíritu cristiano desclericalizado; pero exponía a una tajante crítica también el voluntarismo comunista. Buscaba unir a los intelectuales católicos de ideas sociales.

La publicación de las ideas de Kocbek sobre la guerra civil en España significó la ruptura en la derecha católica eslovena. Era latente ya antes y no se apaciguó. Al contrario: de allí a pocos años el nazifascismo destruyó Yugoslavia. Eslovenia sufrió un desmembramiento entre el III Reich (Carniola superior, Estiria), Italia (Carniola inferior con Ljubljana) y una pequeña parte también de Hungría. Empezó en seguida un período de sublevación y resistencia contra los ocupantes, particularmente encarnizada en el territorio de la ocupación italiana. Edvard Kocbek apoyó la participación de los católicos en la lucha contra el ocupante italiano y tomó desde 1942, coherente a sí mismo, parte activa en ella. Recuerdo que un periódico anticomunista de Ljubljana en aquel tiempo le calificaba desdeñosamente de cristiano rojo. Es verdad que los católicos tuvieron en la lucha por la liberación nacional una situación difícil. Durante la resistencia aumentaba la importancia del Partido Comunista Esloveno (KP), por el hecho innegable de haber tenido una larga experiencia de actividad clandestina, prohibida en la antigua Yugoslavia. Kocbek, personalidad políticamente importante durante la lucha contra el nazifascismo, es decir, en el Frente de Liberación, lo fue cada vez menos y con la toma absoluta del gobierno por parte del Partido Comunista Esloveno llegó a ser innecesario políticamente e incluso a incomodar al nuevo régimen. Terminada la guerra, fue poco a poco «exento» de todas las funciones y en 1952 jubilado. El régimen se aprovechó para ello de la publicación de sus cuatro novelas breves, editadas bajo el título de Strah in pogum (Temor y ánimo), la primera prosa eslovena de posguerra que rompió con la presentación ideologizada de los temas de la Lucha de Liberación Nacional. Fue censurado por completo hasta 1960 y en este período no le fue posible publicar nada. En 1975, una nueva avalancha contra él vino por la publicación 
de su entrevista, con ocasión de sus setenta años, con el importante escritor esloveno de Trieste Boris Pahor, en el periódico triestino Zaliv (Bahía), bajo el título de Edvard Kocbek, pričevalec našega časa (Edvard Kocbek, testigo de nuestro tiempo). En ella, Kocbek con mucho afecto personal habla de la situación del grupo católico en la lucha de la Liberación Nacional, de su destino personal una vez terminada la guerra y también de la ejecución sin proceso judicial de los colaboradores eslovenos con el ocupante, militares y civiles, después de la guerra, restituidos a las autoridades yugoslavas por el ejército británico en Austria. La entrevista suscitó un gran interés, una fuerte consternación también fuera de Eslovenia, mientras que en su propio país se desencadenó una violenta condena política contra el autor.

El propósito de nuestra pequeña contribución es la de presentar brevemente el artículo de Kocbek en Dom in svet de 1937: Meditaciones sobre España. Kocbek, lo repetimos, profundamente cristiano, pensador, exige del cristiano ánimo para exponerse al riesgo, heroismo e inseguridad. Según él, las herejías fueron, en la mayoría de los casos, acciones patentes y no ocultas, es decir, fueron un heroismo espiritual de gente convencida, que se atenía a su conciencia. Dice con dolor que en el presente predomina la mentalidad burguesa, es decir, la negación del espíritu creador en el hombre. El fascismo es, para Kocbek, un movimiento que oculta la realidad social, que esconde la injusticia bajo el abrigo del orden social; que se presenta como garante del orden, la disciplina, la vitalidad, la potencia y el éxito. El fascismo, dice Kocbek, es aún más peligroso que el comunismo, por el hecho de que el comunismo construye abierta y transparentemente su errónea concepción de la vida, mientras que el fascismo construye la suya en aparente congruencia con todos los principios e instituciones espirituales. Kocbek constata con aflicción que la praxis cristiana no excluye una estrecha colaboración de la Iglesia con la combatividad fascista. Es posible que fuese la situación en Italia la que empujó a Kocbek a reflexionar: la jerarquía de la Iglesia en Italia apoyaba fuertemente la política del régimen fascista en la guerra en Etiopía en 1935, y, en 1937, igualmente el alzamiento en España. En la situación española Kocbek ve con todo el dolor la tendencia de la prensa de orientación ideológica católica a hablar continuamente de cruzada contra el bolchevismo, de guerra santa contra los incendiarios de iglesias, contra los asesinos de los sacerdotes, y de no decir nada sobre las causas de esta carnicería y devastación, y nada sobre las atrocidades del campo franquista, que son por lo menos tan grandes como aquellas cometidas por las rabiosas masas populares. Subraya siempre el filósofo esloveno que él no quiere disminuir de ningún modo la culpa de los delitos contra la Iglesia española que, efectivamente, han sido cometidos en gran número y todavía acontecen, escribe. Empero, contradice la insolente aseveración fascista que quiere transmitir el punto esencial del conflicto a otra parte so pretexto de que la guerra civil en España es una guerra de religión. Las profundas razones del conflicto fratricida según su convicción sincera no son de religión sino sociales.

Kocbek está bien informado sobre muchos aspectos de la vida en la España de entonces: sobre la repartición de la tierra cultivable, sobre el malestar de las capas bajas de la sociedad española, sobre el bajísimo nivel de vida de los campesinos, también sobre el estado de analfabetismo, y más aun sobre la debilitación de la verdadera fe. La religiosidad, dice - y está informado por los círculos católicos franceses-, del pueblo que dio a la fe tantos héroes y tantos místicos está, en el último siglo, por perderse en puras fórmulas 
externas. La Iglesia, sobre todo las capas altas de la jerarquía, estaba ligada a la clase dominante de la sociedad española, a la aristocracia terrateniente. Kocbek aduce muchos pensamientos del católico español José María Semprún del que cita su artículo La question de l'Espagne inconnue (Esprit, noviembre 1936). Una gran culpa la ve Kocbek en los sacerdotes como funcionarios, criados en el espíritu feudal y destinados sobre todo a formar «buenos ciudadanos», gente mediocre. En ellos no hay verdadero amor de Cristo. Unas palabras más amargas aún están dirigidas a la alta jerarquía de la Iglesia, a los obispos, que, según Kocbek, están demasiado ligados a los asuntos temporales, materiales, al mundo de la nobleza y de las altas capas de la burguesía, alejados del pueblo modesto. Así, la Iglesia española se puso de la parte de las fuerzas conservadoras, de los ideólogos del orden, de las fuerzas del nacionalismo, porque en la parte opuesta no veía más que desorden, osadía, indecencia y escándalo.

El gobierno de Gil Robles, católico, opina Kocbek, habría podido, quizás, hacer valer los principios cristianos; era, lastimosamente demasiado débil para arreglar la situación social, y por eso la izquierda con el Frente Popular ganó las elecciones en febrero de 1936. Con la guerra fratricida, escribe el filósofo esloveno, el pueblo español quedó mortalmente dividido.

Quien escriba la historia de estos días terribles, desembarazándose de toda simplificación, -esta es su convicción-, tendrá que reconocer que en ambas partes acaecen hechos horribles, las dos partes están manchadas de sangre, ninguno de los dos campos no está sin culpa en suplicios, homicidios, destrucciones por fuego y otros delitos monstruosos. Si como cristianos, concluye Kocbek, de ningún modo podemos aprobar la violencia roja, tampoco y tanto menos podemos pasar por alto el terror blanco. Cita el escrito de un católico español publicado en la revista Esprit (noviembre 1936) Double refus, donde se lee: -Como católicos justamente debemos reprochar a nuestros correligionarios que hayan empezado con la brutalidad siguiendo la regla pagana: diente por diente. A fin de cuenta, la rebelión de los generales fue una insurrección contra el gobierno legítimo. Kocbek subraya que el Alzamiento empezó contra la bolchevización del pueblo español y contra el marxismo y el comunismo. Añade que el cristiano de verdad no puede declarar la concepción comunista ni reconocer como válidas sus ideas, pero escribe, según testimonian muchos juiciosos católicos españoles, en España no hay comunismo. En las Cortes había unos quince diputados comunistas; hablando de la extrema izquierda habría que pensar, si se quiere, en la presencia anarquista.

El filósofo esloveno, repetimos, obtiene sus informaciones a través de las revistas francesas y a través de testimonios personales. Del carácter del hombre español escribe que es muy impulsivo e instintivo. Está convencido de que hay que imputar los vandalismos individuales o de grupos a unas causas particulares, personales. Y, sobre todo, juzga que la mayoría de las acciones desgraciadas, impías no se originan en el odio de la religión, sino en el odio de sus representantes. Dedica, pues, el final de su escrito a la persecución por parte de los franquistas de los sacerdotes del País Vasco que tomaron partido del gobierno legal. Kocbek admira a estos sacerdotes, e igualmente a aquellos en todo el país, que quieren salvar con amor cristiano y fidelidad lo que con la espada no es posible, es decir, el prestigio espiritual de la fe cristiana. Algunas veces toma los informes de la revista católica Cruz y Raya, dirigida por el escritor José Bergamín. De todos modos, está plenamente informado; su círculo francés, y Kocbek con él, seguían con amor y con pasión lo acaecido en España. Por eso puede citar también las declaraciones brutales de generales como Mola, Queipo de Llano, declaraciones que pueden y deben helar a un cristiano, y Kocbek lo fue. 
Su escrito termina con las palabras conmovedoras de eminentes personalidades católicas, citadas por Esprit (enero 1937), cristianos de varias orientaciones ideológicas y políticas, unidos en protesta contra la sed de sangre en esta terrible guerra fratricida, que se preguntan cómo es posible que - después de veinte siglos de cultura cristiana - se atrevan a declararse católicos quienes renuncian a los mandamientos del decálogo divino, quienes rehusan la ética cristiana.

Exponer la guerra civil, la guerra fratricida española de esta manera a los católicos eslovenos, y los lectores de la revista Dom in svet lo eran, fue más que suficiente para la condena de Edvard Kocbek por parte de la facción clerical y la mayoría de la jerarquía católica en Eslovenia.

\section{ŠPANSKA DRŽAVLJANSKA VOJNA IN RAZKOL V SLOVENSKEM KATOLIŠKEM KROGU: EDVARD KOCBEK}

Prispevek je namenjen špansko govoreči sferi. Slovenskemu intelektualcu pač ni potrebno predstavljati politične in kulturne sfere na Slovenskem v letih pred drugo svetovno vojno in tudi ne pojasnjevati vloge Edvarda Kocbeka v katoliški kulturni sredini. V prispevku so podane misli slovenskega filozofa, objavljene v katoliški reviji Dom in svet leta 1937 in posledice te objave. Članek je povzročil pravi razkol: Kocbek, globoko veren krščanski človek, je odločen nasprotnik fašistične miselnosti, ki je v Španiji prevladala z uporom vojske proti zakoniti republikanski vladi. Španskim katolikom in še posebej katoliški hierarhiji očita, da pri tem izgubljajo pravo krščansko vero. Obsoja rdeče nasilje nad špansko Cerkvijo, kot prepričan vernik pa še toliko bolj nasilje uporniške strani, ki je zavrgla krščansko načelo ljubezni do bližnjega. 